\title{
Do robots facilitate life review narratives of older adults? A preliminary study
}

\author{
Anna Ueda $\mathrm{MHS}^{\mathrm{a}, \mathrm{b}, *}$, Hideyuki Takahashi PhD ${ }^{\mathrm{c}}$, Yuichiro Yoshikawa $\mathrm{PhD}^{\mathrm{c}}$, Hiroshi \\ Ishiguro PhD', Haruo Nomura PhD ${ }^{b}$ \\ ${ }^{a}$ Clinical Mental Health Counseling Program, St. Cloud State University, Minnesota, USA; \\ ${ }^{b}$ Graduate School of Human sciences, Osaka University, Osaka, Japan; ' Graduate School \\ of Engineering science, Osaka University, Japan; *Corresponding author: anna.ueda@ \\ go.stcloudstate.edu
}

\begin{abstract}
Background: Life review is a process in which people retrospect and find meaning in past life events, and synthesize these experiences into a narrative. It is usually conducted collaboratively for older adults through a listening partner who works to motivate and stimulate the conversation.

Objective: This study aimed to compare narratives of older adults with human and non-human listening partners during a life review session and to determine whether the participants felt safer in disclosing their private experiences or thoughts without fear of social judgement. Method: We conducted life reviews with 5 older adults using 2 types of speaking partners: a human and a robot. The partner asked a set of structured life review questions designed to trigger a review of past events and gave controlled responses. Two life review sequences comprising 4 sessions each were completed; the first 4 were with a human partner, followed by 4 with a robot partner. There was a 4-week interval between the sequences. The transcribed life review conversations were compared and analyzed qualitatively.

Results: When talking with a human partner, life review narratives showed more awareness of generation gaps compared to the narratives formed with the robot. In contrast, their narratives to the robot partner included more universally transmissive values (Watt \& Wong, 1991; Wong \& Watt, 1991).

Conclusion: This preliminary study was the first attempt to gauge the effects of conducting a life review with robots as partners. The outcome suggests that life review with robots can provide older adults with a unique environment to tell their personal life narratives by allowing them to have different perspectives while reviewing their past. Utilizing both humans and robots in life reviews could help older adults to construct extensive and abundant life narratives in the future.
\end{abstract}

Keywords: robots, life review, older adults, narrative, transmissive values

\section{INTRODUCTION}

Life review refers to the process of recalling life events and narratives while evaluating and giving meaning to them (Butler, 1963; Webster \& Gould, 2007). Giving meaning to life events helps us gain new perspectives on how we perceive and value the past and present (Singer, 2004; McAdams \& McLean, 2013). This study conducted life reviews between older adults and social robots, as well as human partners. The purpose of this study is to introduce a novel style of life review to help older adults create rich narratives and life stories.

Narratives can have a significant impact on our present mental health and well-being. For example, Neimeyer (2000, 2001a, 2001b) considered meaning-making an essential task when faced with the loss of a significant other. Furthermore, Bohlmeijer et al. (2003) indicated statistically and clinically significant effects of life reviews on depressive symptoms in older adults. They concluded that it was a potentially effective treatment for depressive symptoms and would offer a valuable alternative to psychotherapy or pharmacotherapy. Life review therapy is also applied online and has shown its effectiveness in alleviating depressive symptoms in older adults (Bohlmeijer et al., 2017; Westerhof et al., 2019). Many other researchers have reported a significant reduction in the degree of both depression and hopelessness and improved quality of life following life review (Bohlmeijer et al., 2003; Bohlmeijer et al., 2007; Pinquard et al., 2012). Research has also shown that it increased well-being and specific memory in older adults (Lan et al., 2017). Due to these previously reported contributions, life review has attracted the attention of many researchers as a way to intervene in the mental health and well-being of older adults (for example, Westerhof \& Slatman, 2019; Witlox, 2020). 


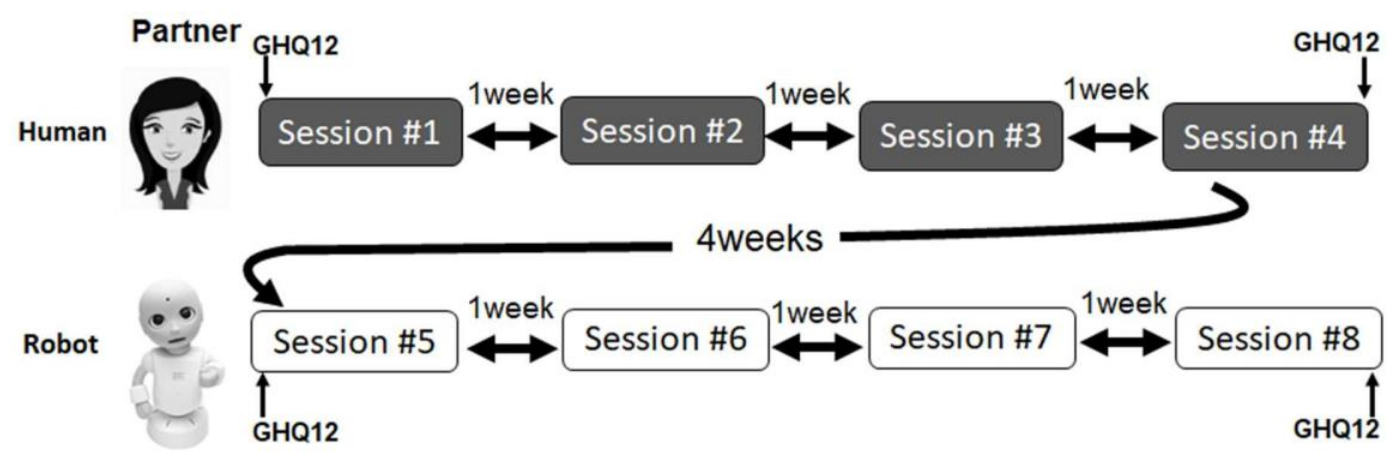

Figure 1. Experimental timeline. GHQ12 denotes each time the General Health Questionnaire 12 was administered

The attributes of life review partners are particularly important. Life review involves telling a narrative to "someone" and constructing stories; it is not solitary work. Partners play an essential role; they are required to be actively involved and do not merely listen passively. They are expected to help speakers find meaning in past events. In this sense, the life review is collaborative work between speakers and partners. The type of meanings that are found and how they are interpreted can be strongly influenced by factors related to the partner such as their attributes, which can include their gender, age, race, and cultural backgrounds along with their personalities and attitudes.

However, people are often unable to open up and speak freely in front of others, because they often worry about the listener's thoughts or intentions toward themselves (Duval \& Wicklund 1973; Wicklund 1975; Silvia \& Duval, 2001). This psychological tendency may affect life review, making people tell narratives selectively, worrying about their social reputation or their partner's potential judgement. Therefore, conducting a stable and effective life review requires the removal of social pressure.

Some studies focusing on self-disclosure have utilized robots as partners to human speakers in order to diminish this social pressure (Kruijff-Korbayová et al., 2014; Uchida et al., 2020). For example, Uchida et al. (2017) showed young adults a list of "life worries" and asked them to choose between a robot and a human to disclose their feelings related to each one. The more serious the worries, the more participants tended to prefer robots. Mumm and Mutlu (2011) reported that people are likely to disclose more extensively to robots. Kumazaki, Warren, et al. (2018) reported that people with autism spectrum disorder (ASD) are more likely than others to choose a robot partner to talk about topics they find shameful or difficult. According to these studies, it is probable that humans reveal more unvarnished and honest narratives to robots because we tend to assume they will not judge or criticize us. Combining these unique features of robots with life reviews for older adults creates a potential opportunity to form unique narratives, resulting in a wider and more diverse process of life meaning-making.

In this study, 5 older subjects practiced life review in 2 settings: first with a human and second with a robot partner, using the same structure. The utterances produced in each setting were qualitatively analyzed and compared. Based on the results, we discuss the possibility of this novel way of conducting a life review, with robots as partners.

\section{Method}

We conducted life review sessions with 5 older subjects. All participants reviewed their lives with a human partner and then a robot partner. They were required to review each life stage of their past (Erikson, 1959), and were asked the same questions by both partners, following the guidelines of structured life review (Haight \& Haight, 2007). We examined how the participants narrated their life stories differently to human and robot partners by analyzing their utterances qualitatively and quantitatively.

\section{Participants}

We recruited 5 healthy older participants (4 males and 1 female) who were active members of local senior clubs and volunteered to participate (mean age $=84$ years; $S D=5.76$ ). This study was designed in accordance with the guidelines of the Declaration of Helsinki and was approved by the research ethics committee at [removed for anonymous review]. All participants were given a sufficient explanation of the experiment and its privacy policy and provided written informed consent. At the end of the final session, each participant was given a 4,000-yen book gift card.

\section{Procedures}

A total of 8 life review sessions were conducted over 10 weeks (Figure 1). Participants had 4 weekly sessions with a human partner; this 
LR with a human

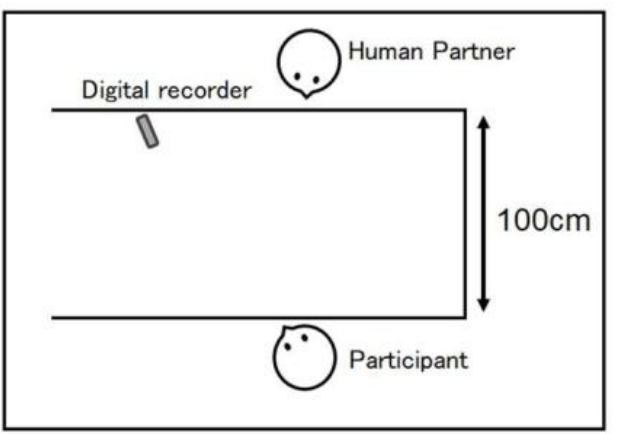

LR with a robot

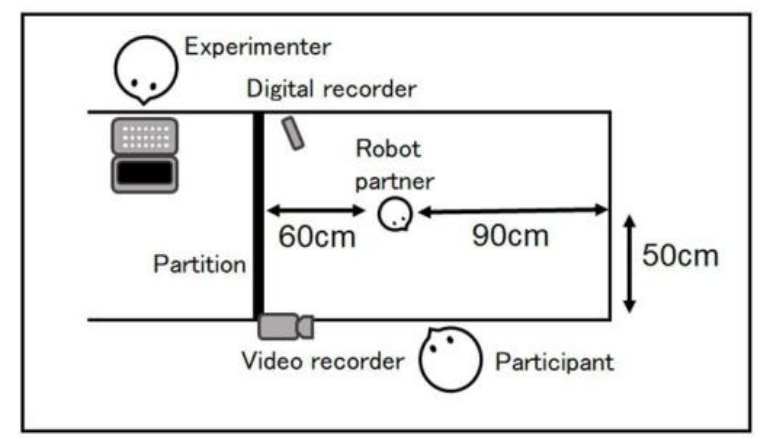

Figure 2. Experimental setup

role was played by one of the study's authors, a Japanese woman in her late 20s. This was followed by an interval of 4 weeks, after which the participants had 4 further weekly sessions with a robot partner. In each session, the human/robot partner asked the questions. Each session took approximately 1 hour. All sessions were recorded. Participants also answered the General Health Questionnaire 12 (GHQ-12), a psychometric screening tool used to identify common psychiatric conditions (Goldberg, 1978). This was used in order to monitor participants' health conditions throughout the experimentation process at four points in total: at the beginning of the first and fifth sessions and at the end of the fourth and eighth sessions. The researcher read all the questions aloud and had the participants point to the relevant answer. Their health conditions were assessed to be satisfactory to participate throughout the experiment, with an average score of 1.05 , which is considered to be a healthy score, at all times.

\section{Robot used in the experiment}

We used a remotely controlled robot, CommU (Vstone Co., Ltd.), a social communication robot with a height of $30 \mathrm{~cm}$ and a human-shaped body that resembles an infant (Shimaya et al. 2019). It only speaks and moves according to the commands of the control computer. On the computer screen, programmed sentences and movements are shown as options to be tapped. CommU talks from a speaker installed in its torso and automatically opens its mouth while producing synthetic voice. The utterances of the robot partner were remotely controlled by the experimenter with a touchscreen who was unable to be seen by the participant. To standardize the utterances of the human and robot partners across participants, the utterances of the human partner were put into the computer as texts and displayed as buttons labeled as texts to be tapped by the experimenter and then spoken by the robot partner. The human partner asked similar questions to all the participants, but her reactive responses to the participants varied and were influenced by the participants' various narratives and contexts. Therefore, the response options for the robot were customized for each participant, based on utterances of the human partner during their life review sessions and basic phrases to promote smooth communication. Basic phrases consisted of seven parts: aizuchi (not proactive but responsive short phrases such as "uh-huh," "I see"), agreeing and understanding, fillers ("umm"), surprise, and admiration ("wow!", "wonderful"); apologies and thanks; yes/no; and clarification questions ("can you tell me more?", "What kind of experience was it?").

Movement functions include nodding, lifting, and averting the eyes, which were added randomly by the experimenter. To ensure that participants were less aware of a human presence nearby, they were not told that the robot was remotely controlled by the experimenter until the end of the last session.

\section{Experimental setting}

All sessions were performed in person in a quiet and private room. In the human-partner sessions, the partner and participant sat down at the desk facing each other. In the robot-partner sessions, the robot was placed on the desk facing the participants and the experimenter sat behind a partition where the participants were unable to see them (Figure 2). The experimenter controlled the robot using a touchscreen interface.

\section{Analysis method}

The coding and analysis were conducted by 2 of the authors (A.U. and H.T.) based on the 6 established phases of thematic analysis (Norwell, 2017). If any disagreement could not be solved, the coding was dropped. In the first step of coding, sentences and utterances containing 3 elements of life review were identified: recall, evaluation, and synthesis (Webster \& Young, 1988). These were statements by participants that recalled their life events, and the connections and 


\begin{tabular}{r|cc:c|c|c|c|} 
& Evaluation & Realization & $\begin{array}{c}\text { Giving } \\
\text { a significance }\end{array}$ & Processing & $\begin{array}{c}\text { Generation } \\
\text { gap }\end{array}$ & $\begin{array}{c}\text { Transmissive } \\
\text { Values }\end{array}$ \\
\cline { 2 - 8 } Human & 0.60 & 0.14 & 0.00 & 0.02 & 0.10 & 0.14 \\
Robot & 0.63 & 0.13 & 0.00 & 0.04 & 0.01 & 0.19 \\
\cline { 2 - 8 } Human & 0.79 & 0.04 & 0.03 & 0.02 & 0.09 & 0.04 \\
Robot & 0.78 & 0.03 & 0.01 & 0.02 & 0.05 & 0.12 \\
\cline { 2 - 8 } Human & 0.84 & 0.08 & 0.00 & 0.01 & 0.06 & 0.02 \\
Robot & 0.85 & 0.02 & 0.01 & 0.01 & 0.04 & 0.07 \\
Human & 0.84 & 0.02 & 0.04 & 0.00 & 0.05 & 0.05 \\
Robot & 0.82 & 0.00 & 0.02 & 0.00 & 0.04 & 0.12 \\
\cline { 2 - 7 } Human & 0.91 & 0.02 & 0.00 & 0.02 & 0.03 & 0.03 \\
Robot & 0.85 & 0.04 & 0.00 & 0.00 & 0.02 & 0.10 \\
\cline { 2 - 8 } & & & & & &
\end{tabular}

\begin{tabular}{l|cc:c:c:c:c|} 
A & -0.03 & 0.01 & 0.00 & -0.01 & 0.09 & -0.05 \\
B & 0.01 & 0.01 & 0.01 & 0.00 & 0.04 & -0.08 \\
\hdashline C & -0.01 & 0.06 & -0.01 & 0.00 & 0.02 & -0.05 \\
\hdashline$D$ & 0.02 & 0.02 & 0.02 & 0.00 & 0.01 & -0.07 \\
E & 0.06 & -0.02 & 0.00 & 0.02 & 0.01 & -0.06 \\
\hline
\end{tabular}

Figure 3. The ratio of the number of units in each evaluation type in summed units of all 6 evaluation types (upper part); the difference of ratio between partners (human minus robot; bottom part)

meanings they have for their present lives. In the process of identifying these targeted sentences, the authors established 6 types of evaluation and meaning-making as follows (Table 1):

- Evaluation: evaluation of themselves and other people, things, and experiences important to them

- Realization: gaining new perspectives while narrating

- Giving significance: attaching meanings to past events in new contexts

- Processing: trying to process and understand while narrating

- Generation gap: comparisons of older and younger generations

- Transmissive values: values to be transmitted to the next generation, including their own life principles.

To analyze the frequency of each utterance type, the sentences were combined or divided to form a unit of measurement representing one of the 6 types of evaluation per topic/context. The frequency of each type was compared between the human- and robot-partnered life reviews and the utterances in each type were qualitatively analyzed.

To find differences in the participants' utterances when talking to a human and a robot, the recorded material was transcribed and analyzed using text mining. The software Mtminer, which was developed to analyze the text of narratives close male friends), and boku (also masculine, seen as more polite; used either in public or among friends). The second area is related to significant people (e.g., friends, teachers, parents), and the last area focused on affiliations or groups (e.g., junior high school, company). In the Japanese language, different personal pronouns are used depending on proximity and type of social relationship. We assumed that through the analysis of personal pronouns used (specifically, firstperson pronouns), we would be able to elucidate the psychological distance between the participants and their human or robot partner. After the words were screened, their occurrence was analyzed using PCA. From this, principal component plots with the top 2 eigenvalues were created.

\section{Results}

All GHQ-12 conducted at four points of the experiments showed that all of the participants indicated no seriousness in their psychiatric health conditions before and after the life review sessions with human and robot partners. The ratio of the number of units corresponding to each evaluation type and the summed units of all 6 evaluation types in both settings (human/robot partner) were calculated (Figure 3). The difference in the ratios between the 2 settings was also calculated (human-robot, as shown in the lower part of Figure 3). In the upper part of Figure 3 , the intensity of the red color corresponds 
Table 1. Frequency of occurrence of 6 evaluation types

\begin{tabular}{lcccccc}
\hline & Evaluation & Realization & $\begin{array}{c}\text { Giving a } \\
\text { significance }\end{array}$ & Processing & $\begin{array}{c}\text { Generation } \\
\text { comparison }\end{array}$ & $\begin{array}{c}\text { Transmissive } \\
\text { values }\end{array}$ \\
\hline Human & 82 & 19 & 0 & 3 & 14 & 19 \\
Robot & 86 & 17 & 0 & 5 & 2 & 26 \\
Human & 153 & 8 & 5 & 3 & 17 & 8 \\
Robot & 137 & 5 & 2 & 3 & 8 & 21 \\
Human & 104 & 10 & 0 & 1 & 7 & 2 \\
Robot & 84 & 2 & 1 & 1 & 4 & 7 \\
Human & 116 & 3 & 5 & 0 & 7 & 7 \\
Robot & 97 & 0 & 2 & 0 & 5 & 14 \\
Human & 107 & 2 & 0 & 2 & 3 & 4 \\
Robot & 95 & 4 & 0 & 0 & 2 & 11 \\
\hline
\end{tabular}

"Life is not smooth sailing. It was not until I overcame painful experiences that I was able to have the serenity that I have now."

\section{Transmissive values}

The contents of transmissive values which exhibited the most significant gap between the 2 settings, were identified, ana-

to the percentage of total categories; the higher ratio is presented in darker red. In the lower part of Figure 3, the human-robot difference ratio corresponds to the intensity of red/blue colors. The higher the ratio of the appearance of units with a human partner, the darker the red; blue denotes the opposite case.

Evaluation was the most common utterance category among all 5 participants. In the comparison of human-robot ratios, all participants made more transmissive values utterances with the robot than the human; all other evaluations tended to be told more to the human partner. The generation gap was mentioned more often to the human partner by all 5 participants.

\section{Examples of 6 evaluation types}

Evaluation

"I didn't want to do it in front of people ... I guess I didn't have confidence in myself at the time."

\section{Realization}

"When I think about it now ... let's see ... I learned about society and the factory from these experiences, I guess."

\section{Giving a significance}

"I guess so ... When I was young, I experienced wars, struggled to find food. I had a hard time in many ways, but I think I would not have become the person I am today if I had not been able to overcome these hardships by staying healthy and working hard."

\section{Processing}

"Well, I don't know if it was because my parents gave me a healthy body or if it was because I was a sports fanatic, but I was strong and healthy."

\section{Generation gap}

"When we were young, boys and girls were not allowed to be intimate with each other at school."

Transmissive values lyzed, and categorized by theme. Similar utterances were grouped into categories, and each category was labeled. Eventually, 8 categories were established: personal values, human nature, attitudes toward life, self-effort, interpersonal relations, insight, encouragement, and tradition. These values are detailed as follows:

\section{Personal values}

The individual's moral principles and ethical priorities.

\section{Human nature}

The general innate but flexible characteristics of humankind as a whole, comprising the set of behaviors, attitudes, and dispositions that typify the human race.

\section{Attitude to life}

A relatively enduring and general evaluation of life ranging from negative to positive.

\section{Self-effort}

A sense of effort or overcoming resistance with oneself usually entailing a sense of achievement.

Interpersonal relations

The connections, interactions, and the patterns observable between 2 or more people.

\section{Insight}

Awareness of underlying sources of emotional, cognitive, or behavioral responses and difficulties with oneself or another person.

\section{Encouragement}

Words that give someone confidence to do something.

\section{Tradition}

A set of social customs or ethnic or family practices handed down from generation to generation.

A common finding among all participants was that the narratives they told to the robot included more transmissive values. In other words, person- 

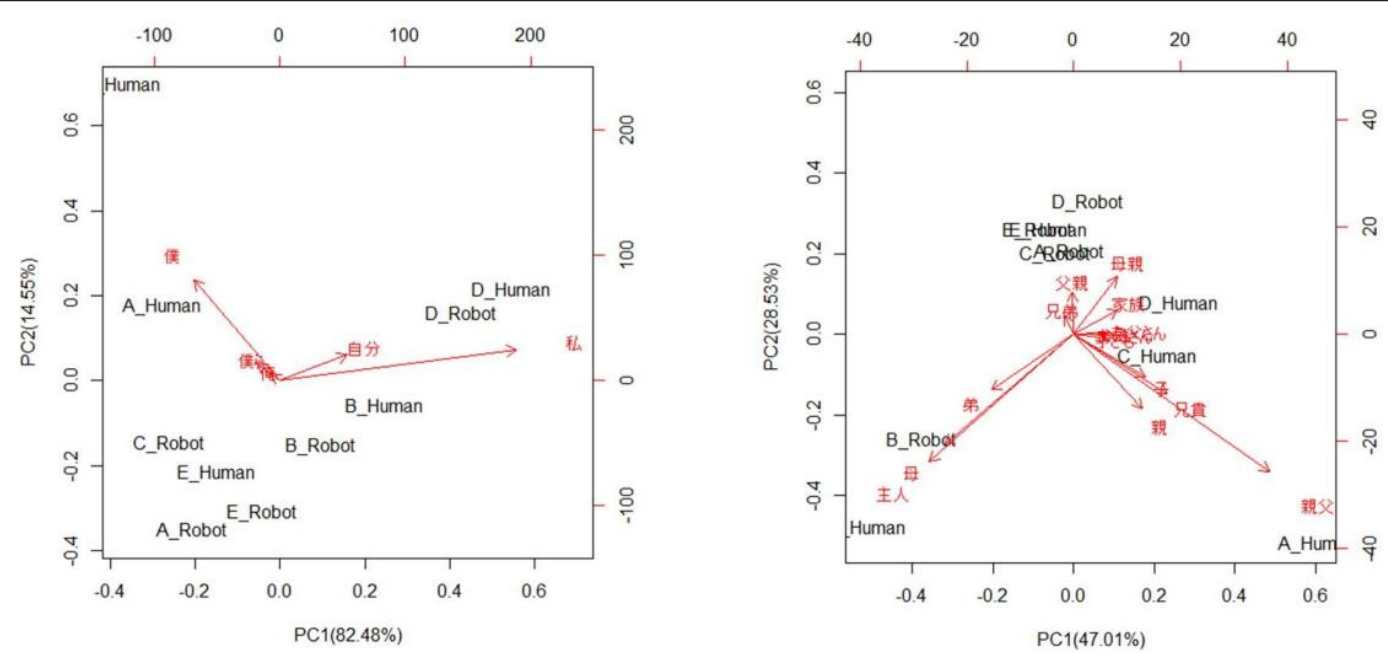

Figure 4. PCA of pronouns of the first person (left) and words related to significant persons (right). The closeness of the position of the plots indicates that the trends in the frequency of occurrence of the words are similar. The red arrows indicate the directions of more frequently used words, and the length of the vectors indicates the factor loading of the words

al values and self-effort were more frequently disclosed. Other types of transmissive values were stated differently among the participants. The contents of the transmissive values mentioned to the human/robot listeners by each participant are explained briefly below. The Appendix indicates the list of all categorized narratives.

\section{Participant A}

Utterances about personal values, human nature, and self-effort were made more frequently to the robot than the human listener, whereas attitude to life was stated more to the human partner. In the category of interpersonal relations, in particular, Participant A spoke more about the topic of friends. Participant A's tone of voice was notably softer to the robot.

\section{Participant $B$}

The number of utterances about attitude to life and self-effort was greater with the robot. Participant $B$ especially expressed pride to the robot that she had been determined to set her own goals and carved out a career for herself. Participant B repeatedly emphasized the importance of friends and of being modest in life to the human partner, but these topics were not mentioned to the robot. Participant B was also noted to use a softer voice with the robot.

\section{Participant C}

A larger number of transmissive values were found in the narratives told to the robot. Personal values and encouragement only appeared when speaking to the robot. Regarding narratives that included values with both partners, Participant C tended to see his experiences as more successful and used more direct expressions to the robot.
Participant $\mathrm{C}$ also expanded on topics with the robot in more depth; for example, he recounted the details of his children, family, and his health.

\section{Participant D}

In the category of personal values, attitude to life, self-effort, and interpersonal relations, Participant $\mathrm{D}$ discussed more of those values with the robot. Participant D expressed opinions on personal values to the robot that he did not tell the human speaker, including topics of educational policy, maternal roles in caregiving, and respect for the elderly.

\section{Participant $E$}

Participant E repeatedly emphasized the importance of having global perspectives to both speaking partners. Participant E seemed more eager to discuss his message in greater detail with the robot.

\section{Text mining}

PCA was performed to identify the frequency of words in the participants' utterances. The first area was pronouns, including first-person pronouns (e.g., watashi, a formal pronoun in Japanese), ore (masculine pronoun, usually used among close-male friends), boku (also masculine, seen as more polite; used either in public or among friends). The second area is related to significant people (e.g., friends, teachers, parents). The results of the 5 participants in both settings are shown as plots with the top 2 eigenvalues in the 2-dimensional space in Figure 4. The closeness of the position of the plots indicates that the trends in the frequency of occurrence of the words are similar. The red arrows indicate the directions of more frequently used words, and the 


\section{Do robots facilitate life review narratives of older adults?}

length of the vectors indicates the factor loading of the words.

\section{Pronouns of the first person}

Participants B, D, and E used similar words with both partners, whereas participants $\mathrm{A}$ and $\mathrm{C}$ tended to use different words. Participants $\mathrm{A}$ and $C$ used boku and bokura (plural form) more often with the robot partner.

\section{Words related to significant people}

All participants used a variety of words and no common tendency was found.

From the above results, it was shown that Participants $A$ and $C$ tended to have a larger difference in pronouns and topics spoken with the 2 types of partners, while Participants $B, D$, and $E$ had less of a difference.

\section{Discussion}

The novelty and significance of this research lie in practicing life review with older adults using a robot as a partner, and qualitatively analyzing and comparing their utterances to robot and human partners. To the best of our knowledge, no similar research has been conducted on this topic. Thus, this research potentially has great value for future studies. Our results reveal differences in the utterances of older adults between human and robot partners, especially in the frequency of transmissive values. Furthermore, text mining analyses showed differences in the use of words between human and robot partners.

Previous research noted that robot partners helped subjects self-disclose more freely compared to human partners. For example, Uchida et al. (2017) reported that participants tended to speak more about negative topics with robots. Kumazaki Warren, et al. (2018) revealed that ASD participants who had difficulties in interpersonal communication disclosed themselves eagerly to robots. Tardy and Smithson (2018) developed a hypothesis to explain these phenomena: when people are afraid of being judged or fear revealing weaknesses, they limit their narratives when speaking to other humans, especially when the listeners are close or of higher social status. Therefore, social robots allow participants to show more vulnerability due to their lack of social position, tendency to judge others, and ability to apply social pressure. This hypothesis applies to the results of our study, in which older adults showed clear differences when speaking to humans. For example, people may be reluctant to talk about transmissive values, which were spoken about more openly to the robot by each participant, because they contain personal or generational values. In such cases, younger people or other close listeners may judge, mock, or not take their ideas seriously. Older adults may have felt more comfortable speaking with the robot, as they did not need to fear this sense of judgment.

The significance of narrating a life story lies not in eliciting an accurate description of the past, but in articulating various topics and reflecting on their meanings and values. James et al. (1998) contended that older adults are more likely to be verbose and reflect on the importance of their narration. If robots could serve as partners to facilitate older adults' reflection, enabling them to construct different or undiscovered narratives, this may increase the flexibility of life review narratives. By exploring and defining the advantages and disadvantages of human and robot life review partners, it may be possible to establish an environment where humans and robots take supplementary roles for older adults' life reviewing process in the future. This will help older adults reconstruct a more flexible meaning for their lives.

There are some limitations to the experimental protocol. This research was a case report of only 5 elderly participants; therefore, statistical analysis could not be performed, and the results should not be overly generalized. Additionally, the experimental protocol may not be well controlled from the viewpoint of laboratory studies. First, there is an issue pertaining to the participants' acclimation. In the experiment, all participants initially spoke to a human and then to a robot in their life review, to control the utterances of the 2 partners. The first 4-week life review with a human partner may have acclimated the participants to the narration setting and influenced their subsequent utterances with the robot partner. If the participants were acclimated to the life review process, it is plausible that the number of utterances would increase with the robot. However, the number of utterances containing evaluation, the life review element we extracted to analyze, showed no significant differences. Considering that the participants started to disclose private topics at an earlier stage with their human partners, acclimation should not be a major factor influencing whether participants discussed topics containing personal values to the robot more frequently. Future research with an increased number of participants and with a converse order of partner types should be conducted to improve the experiment. This will help identify the prevalent characteristics found in older adults' utterances to robots.

The second issue pertains to the limitations of the capabilities of the robot. In the experiment, the older participants had a harder time understanding the utterances of the robot when it spoke unclearly, or when the narrators and the robot started speaking at the same time. The features 


\section{Do robots facilitate life review narratives of older adults?}

of the robot (its infant-like shape) may also have influenced the results of the experiment. Matsui and Yamada (2018) contended that the appearance of robots influences people's impressions of and emotions about robots. Future research may include practice experiments with robots of different sizes, shapes, and voices (Chao \& Thomaz, 2010; Matsui \& Yamada, 2018; Phillips et al., 2017; Nishio et al., 2018). Specifically, what aspects of robots influence the older adults' narratives need to be studied under controlled settings.

Although this study requires more detailed and accurate development, as the first case report exploring the traits of older adults' life narratives when talking with robots, the findings can play a valuable role in the application of life review. Previous research has shown the effectiveness of life review in increasing well-being and reduc-

\section{Acknowledgements}

This work was supported in part by the JSPS KAKENHI Grant Numbers JP20H00101 and in part by the JSPS/ MEXT Topic-Setting Program to Advance Cutting-Edge Humanities and Social Sciences Research JP17J0011b.

\section{References}

Bohlmeijer, E., Smit, F., \& Cuijpers, P. (2003). Effects of reminiscence and life review on late-life depression: A meta-analysis. International Journal of Geriatric Psychiatry, 18(12), 1088-1094.

Bohlmeijer, E., Roemer, M., Cuijpers, P., \& Smit, F. (2007). The effects of reminiscence on psychological well-being in older adults: Ameta-analysis. Aging Mental Health, 11(3), 291-300.

Bohlmeijer, E., Lamers, S., Postel, M., \& Westerhof, G. J. (2017). A Quantitative and qualitative evaluation of an online life review intervention for depression. Innovation in Aging, 746-747.

Butler, R. N. (1963). The life review: An interpretation of reminiscence in the aged. Psychiatry, 26, 65-76

Chao, C., \& Thomaz, A. L. (2010). Turn taking for human-robot interaction. In 2010 AAAI Fall Symposium Series (pp. 132-134). Association for the Advancement of Artificial Intelligence.

Duval, S., \& Wicklund, R. A. (1973). Effects of objective self-awareness on attribution of causality. Journal of Experimental Social Psychology, 9(1), 17-31.

Erikson, E. H. (1959). Identity and the life cycle: Selected papers. International Universities Press.

Goldberg, D. P. (1978). Manual of the General Health Questionnaire (NFER-NELSON, Windsor).

Haight, B. K., \& Haight, B. S. (2007). The handbook of structured life review. Health Professions Press.

James, L. E., Burke, D. M., Austin, A., \& Hulme, E. (1998). Production and perception of "verbosity" in younger and older adults. Psychology and Aging, 13(3), 355-367. https://doi.org/10.1037/08827974.13.3.355.

Karmiyati, D., Rahmadiani, N., \& Hasanati, N. (2020). Life review therapy for improving the psychological wellbeing of elderly retired women in Indone- ing depression levels (Chaing et al., 2008; Pot et al., 2010; Karmiyati et al., 2020); however, it is extremely difficult to provide the opportunity to all patients seeking this because of the cost involved. Life review is a psychologically and financially costly practice, especially for partners, as they must maintain constant and careful attention to older adults during their narrative journey. The partners must constantly work to secure and protect private and personal information from disclosure (Korte et al., 2015). Robots would make life review safer and more accessible, and provide a more comfortable opportunity to construct narratives. Thus, the study of life review utilizing robots highlights the potential for a promising future in which the well-being of older adults will improve. This study has made a big step in cultivating novel life review practices for the overall improvement of societal well-being.

sia. Journal of Social Studies Education Research, 11(4), 257-274.

Korte, J., Majo, M. C., Bohlmeijer, E. T., Westerhof, G. J., \& Smit, F. (2015). Cost-effectiveness of life-review for older adults with moderate depressive symptomatology: A pragmatic randomized controlled trial. Journal of Aging Studies, 34, 146-154.

Kumazaki, H., Yoshikawa, Y., Yoshimura, Y., Ikeda, T., Hasegawa, C., Saito, D. N., Tomiyama, S., An, K., Shimaya, J., Ishiguro, H., Matsumoto, Y., Minabe, Y., \& Kikuchi, M. (2018). The impact of robotic intervention on joint attention in children with autism spectrum disorders. Molecular Autism, 9(1), 1-10.

Kumazaki, H., Warren, Z., Swanson, A., Yoshikawa, Y., Matsumoto, Y., Takahashi, H., Sarkar, N., Ishiguro, H., Mimura, M., Minabe, Y., \& Kikuchi, M. (2018). Can robotic systems promote self-disclosure in adolescents with autism spectrum disorder? A pilot study. Frontiers in Psychiatry, 9, 36.

Kruijff-Korbayová, I., Oleari, E., Baroni, I., Kiefer, B., Zelati, M. C., Pozzi, C., \& Sanna, A. (2014). Effects of off-activity talk in human-robot interaction with diabetic children. In The 23rd IEEE International Symposium on Robot and Human Interactive Communication (pp. 649-654). IEEE.

Lan, X. Y., Xiao, H. M., \& Chen, Y. (2017). Effects of life review interventions on psychosocial outcomes among older adults: A systematic review and metaanalysis. Geriatrics \& Gerontology International, 17, 1344-1357.

Matsui, T., \& Yamada, S. (2018). Robot's impression of appearance and their trustworthy and emotion richness. In 2018 27th IEEE International Symposium on Robot and Human Interactive Communication (RO-MAN) (pp. 88-93). https://doi. org/10.1109/ROMAN.2018.8525796.

McAdams, D. P., \& McLean, K. C. (2013). Narrative identity. Current Directions in Psychological Science, 22(3), 233-238.

Montazeri, A., Harirchi, A. M., Shariati, M., Garmaroudi, G., Ebadi, M., \& Fateh, A. (2003). The 12-item General Health Questionnaire (GHQ-12): Trans- 
lation and validation study of the Iranian version. Health and Quality of Life Outcomes, 1(1), 66.

Mumm, J., \& Mutlu, B. (2011). Human-robot proxemics: Physical and psychological distancing in humanrobot interaction. In Proceedings of the 6th International Conference on Human-Robot Interaction (pp. 331-338). IEEE.

Neimeyer, R. (2000). Searching for the meaning of meaning: Grief therapy and the process of reconstruction. Death Studies, 24(6), 541-558. https:// doi.org/10.1080/07481180050121480

Neimeyer, R. (Ed.). (2001a). Meaning reconstruction and the experience of loss. Washington, DC: American Psychological Association.

Neimeyer, R. A. (2001b). Reauthoring life narratives: Grief therapy as meaning reconstruction. The Israel Journal of Psychiatry and Related Sciences, 38(3/4), 171-183.

Nishio, S., Ogawa, K., Kanakogi, Y., Itakura, S., \& Ishiguro, H. (2018). Do robot appearance and speech affect people's attitude? Evaluation through the ultimatum game. In H. Ishiguro \& F. Dalla Libera (Eds.), Geminoid Studies (pp. 263-277). Springer, Singapore.

Noguchi, Y., Kamide, H., \& Tanaka, F. (2020). Personality traits for a social mediator robot encouraging elderly self-disclosure on loss experiences. ACM Transactions on Human-Robot Interaction (THRI), 9(3), 1-24.

Nowell, L. S., Norris, J. M., White, D. E., \& Moules, N. J. (2017). Thematic analysis: Striving to meet the trustworthiness criteria. International Journal of Qualitative Methods, 16(1), 1609406917733847.

Phillips, E., Ullman, D., de Graaf, M. M. A., \& Malle, B. F. (2017). What does a robot look like?: A multi-site examination of user expectations about robot appearance. Proceedings of the Human Factors and Ergonomics Society Annual Meeting 61, 1, 1215-1219.

Pot, A. M., Bohlmeijer, E. T., Onrust, S., Melenhorst, A. S., Veerbeek, M., \& De Vries, W. (2010). The impact of life review on depression in older adults: A randomized controlled trial. International Psychogeriatrics, 22(4), 572-581.

Pinquard, M., \& Forstmeier, S. (2012). Effects of reminiscence interventions on psychosocial outcomes: A meta-analysis, Aging Mental Health, 16(5), 541-558.

Shimaya, J., Yoshikawa, Y., Kumazaki, H., Matsumoto, Y., Miyao, M., \& Ishiguro, H. (2019). Communication support via a tele-operated robot for easier talking: Case/laboratory study of individuals with/ without autism spectrum disorder. International Journal of Social Robotics, 11(1), 171-184.

Singer, J. A. (2004). Narrative identity and meaning making across the adult lifespan: An introduction. Journal of Personality, 72(3), 437-460.

Silvia, P. J., \& Duval, T. S. (2001). Objective self-awareness theory: Recent progress and enduring problems. Personality and Social Psychology Review, 5(3), 230-241.

Tardy, C. H., \& Smithson, J. (2018). Self-disclosure: Strategic revelation of information in personal and professional relationships 1 . In H. Owen (Ed.), The handbook of communication skills (pp. 217-258). Routledge.

Uchida, T., Takahashi, H., Ban, M., Shimaya, J., Minato, T., Ogawa, K., Yoshikawa, Y., \& Ishiguro, H. (2020). Japanese young women did not discriminate between robots and humans as listeners for their selfdisclosure-pilot study-. Multimodal Technologies and Interaction, 4(3), 35.

Uchida, T., Takahashi, H., Ban, M., Shimaya, J., Yoshikawa, Y., \& Ishiguro, H. (2017). A robot counseling system-What kinds of topics do we prefer to disclose to robots? In 2017 26th IEEE International Symposium on Robot and Human Interactive Communication (RO-MAN) (pp. 207-212). IEEE.

Watt, L. M., \& Wong, P. T. (1991). A taxonomy of reminiscence and therapeutic implications. Journal of Gerontological Social Work, 16(1-2), 37-57.

Webster, J. D. \& Gould, O. (2007). Reminiscence and vivid personal memories across adulthood. The International Journal of Aging and Human Development, 64(2), 149-170.

Westerhof, G. J., \& Slatman, S. (2019). In search of the best evidence for life review therapy to reduce depressive symptoms in older adults: A meta-analysis of randomized controlled trials. Clinical Psychology: Science and Practice, 26(4), e12301.

Westerhof, G. J., Lamers, S. M., Postel, M. G., \& Bohlmeijer, E. T. (2019). Online therapy for depressive symptoms: An evaluation of counselor-led and peer-supported life review therapy. The Gerontologist, 59(1), 135-146.

Wicklund, R. A. (1975). Objective self-awareness. In Advances in experimental social psychology (Vol. 8, pp. 233-275). Academic Press.

Witlox, M., Garnefski, N., Kraaij, V., Simou, M., Dusseldorp, E., Bohlmeijer, E., \& Spinhoven, P. (2020). Prevalence of anxiety disorders and subthreshold anxiety throughout later life: Systematic review and meta-analysis. Psychology and Aging.

Wong, P. T., \& Watt, L. M. (1991). What types of reminiscence are associated with successful aging? Psychology and Aging, 6(2), 272-279.

\section{Appendix I: Participants' narratives CONTAining TRANSMISSIVE VALUES \\ Participant A \\ To human}

Personal values

- Boys must have a fight or two!

Attitude to life

- People will be exhausted if they live in a clever and cunning way.
- Live plain and normally.

- It's important to play fair.

- If you consume the same energy as you jog, you might as well clean the parks.

- Do something useful for others.

- Appreciate your environment always, and try your best.

- I am who I am, going my own way.

Self-effort 


\section{Do robots facilitate life review narratives of older adults?}

- When it's bad, you have to bear it.

Interpersonal relations

- If you maintain good relationships with others, you can live easily, even if you fall, it can be fixed.

-While expressing your opinion, being balanced is what is called cooperation.

- We don't live alone. Helping each other and being flexible is what I like.

- Supporting and being supported is the most important thing I guess.

Insight

- You shouldn't marry someone just because you like them.

- When you crawl on the ground, when you see one step down from others, you can see things better.

Encouragement

- What to do in this world, is your job.

Generation gap

- We have to pass it to the future!

Tradition

- It's not our culture if we lose our heart.

To robot

Personal values

- Happiness - its standard varies depending on people.

- Yes, so, knowledge is not sufficient in society.

Human nature

- Becoming a good person or a bad person what is around us changes us?

- People are kind when you travel.

Self-effort

- You cannot work if you do not like your job, right. It is not all about the paycheck.

- Reading a lot is good.

- You need to experience more by talking with me, right.

- Overcoming hardships, you are able to live calmly, like it is now.

- You have to be patient when in need, and you will enjoy it when you can.

Interpersonal relations

- So, you should make good friends.

- It is important to make true friends.

- You have to try hard to look for friends.

- It's better to have more friends.

- It's so important to encounter true friends.

- Keep good relationships with care.

Insight
- It's hard to tell true friends, but they can be your true friends.

Encouragement

- I wish you the best of luck for the future.

Tradition

- Japanese people have forgotten their culture... it's such a pity.

\section{Participant B}

To human

Personal values

- When I see women smoking, I definitely want to tell them to stop smoking!

- If you chit-chat too much, some problems arise, right? I would never do that.

Self-effort

- I think it's better to have a desire to do something rather than having nothing.

- I never gave up, that made me who I am, I guess.

- If you think negatively, it is not good. So, I take everything in a positive way.

Attitude to life

- But I experienced various things, and they have been useful.

Interpersonal relations

- Well, I had various people to learn from ... being alone I'm immature so ... seeing people is always ... life is learning.

Insight

- When you date someone, you have to date for a long time.

To robot

Personal values

- I think the most important thing is that you have to be kind to others.

- Eating is very important in life. Eat well and enjoy it with everyone.

- I want everyone to take care of things.

- I think the most important thing is that everyone is still healthy.

Attitude to life

- I have experienced many things, and I have already done what I could. I think my life was better off because I did these things.

- After all, when you are alone, the more things you do, the better it is for you.

- Everything should be interpreted in a positive way.

- If you think about bad things all the time, you will not move forward. It is best to forget bad things.

- I try not to remember much about my mother's death. I only remember that I am happy. 


\section{Do robots facilitate life review narratives of older adults?}

- You have to take the parts that are appropriate for you and do it.

Self-effort

- I have to do my own things. I have to live my life as a woman.

- I've always thought that you shouldn't rely on people.

- I had to have a family of my own and get it together. I had to be quick and efficient. Thus, failure is the basis for success.

- If you do not teach, you will not learn. To teach, you have to learn.

- Life should not be given up.

- You have to do your own things. No one else will decide for you.

- Develop the ability to act and think.

- We should do everything with a goal in mind. If you do not achieve it, you are still not trying hard enough or it's not right for you.

- If you do not do it yourself, no one else will, so that is important.

Interpersonal relations

- I want to get along...get along well and respect older people.

- You should get along with people and respect your superiors after all. Tradition

- We need to keep the knowledge of traditional Japanese culture alive and everyone should continue to do so.

\section{Participant C}

To human

Self-effort

- You have to be the one to make an effort in some cases. Interpersonal relations

- It is important that relationships with others are done well.

\section{To robot}

Personal values

- I think supporting a family is a man's duty. That is, we can work hard in a sense.

- I wanted my children to grow up, like me ... to stand on my own feet.

- What is important in life is to make an effort to live a life being honest, and not to be sick. Good health is essential.

Self-effort

- It makes a big change whether you make the effort or not at that point.

- When young, people should make their best efforts and study. Well, if you work hard, everybody will be successful.

Interpersonal relations

- Having the trust of other people, not lying or deceiving, living life with an honest attitude is very important.
Encouragement

- There are many joyful and challenging things in life. I want young people to overcome the challenges and have a happy life.

\section{Participant D}

To human

Personal values

- You should respect other people's values and have your own opinion.

- The more experienced the person is, the more suitable they are for big roles.

Human nature

- I think it is precious that we treat each other equally when we get old.

Attitude to life

- I guess ... do the best you can sincerely in the position you are in, just as much as you can.

Interpersonal relations

- I want you to try to put yourself in others' shoes.

- Think about others and put yourself in their shoes.

Tradition

- Not having enough food, we have experienced these kinds of things. I want to tell the story, although it is difficult.

\section{To robot}

Personal values

- Children as young as two years old still need their parents to pat them on the buttocks.

- There is no useless life. I knew that one experience would definitely come in handy later.

- If you live to be 50 or 60, you will be happy, even if you are poor.

- Respecting the elderly is a natural thing. You have to keep it in your mind.

- I think it is good for children to be taken care of at home by their mothers until elementary or middle school. It is rational to have a bigger family, as in old times.

\section{Human nature}

- I think it would be easier if you did not have to deal with the fact of who is older and younger.

Attitude to life

- I think for the rest of my life, if I am doing the best I can at the time, will be fine. I love the phrase "Que sera, sera."

- We all experience things differently and live in different environments.

- Don't be sloppy. Try hard.

Self-effort

- I think if we just do the best we can, the best we can, that's all that matters. 


\section{Do robots facilitate life review narratives of older adults?}

- I think it's important to keep doing this every day so that you avoid losing strength as much as possible.

\section{Interpersonal relations}

- I find it very sad that someone cannot try to accept the kindness of others.

- It is very difficult to get the right feeling to understand the other person's feeling. I think you have to make mistakes repeatedly to understand.

- I think it is important to make a couple of friends that you can trust $100 \%$.

\section{Participant E}

To human

Personal values

- I want young people to go and see the world. I want them to study English.

- Unless you keep watching the world, you will be outdated.

Attitude to life

- Forecast - when you manage you have to forecast and make proper plans. You cannot be irresponsible.

Insight

- You have to see their personality for sure.

To robot

Personal values
- You should be able to communicate with people around the world.

- Another thing is that I want Japanese people to see the world, not only our own country. I want them to experience it on their own.

- I want everyone to have good relationships with other countries.

Human nature

- So, those who do not have such work need someone to talk with.

Attitude to life

- You have to make your own future by yourself. You cannot depend on others. So, always, think of bigger pictures and widen your perspectives. This is necessary.

- My failure ... but seeing it in the whole picture of my life ... If you stick to it and live day by day, you can keep it going.

Insight

- How you judge them is important after all.

Tradition

- By going abroad, what I learned was that we had to reflect on history.

- I appreciate peace in the world. I want our future to be peaceful. This is why there should be no war. 